RESEARCH

Journal of Critical Dietetics

ISSN 1923-1237

Vol 6, Issue |

Copyright 2021

Toronto, $\mathrm{ON}$

\title{
Opening the door to dialogue: Experiences from equity- seeking students in dietetic education
}

\author{
Mikahelia Wellington, MPH, RD, Meaghan Lee, MPH, RD; Eric Ng, MPH, RD \& Rosie Mensah, MPH, RD
}

\begin{abstract}
Lack of diversity and barriers persist for marginalized students both when entering the dietetic profession and during their education. Through generative dialogue, as four dietitians in Canada, we discussed and reflected on our experiences in dietetic education and training. Our dialogue generated three themes: barriers, belonging, and resilience. We concluded by providing key recommendations for dietetic educators to support the learning of students from marginalized communities and call for difficult conversations about social justice in dietetic education.
\end{abstract}

\section{Background \& Inspiration}

The motivation to initiate this discussion was by no means serendipitous. Conversations surrounding inequity, belonging, acceptance, and justice are common for individuals coming from marginalized communities living in Canada. Three of us were dietetic students in a graduate dietetic training program while EN was one of our instructors. It was through conversations about social justice that we learned about our shared interest in working with marginalized communities. This shared interest stemmed from our own experiences as members of various equity-seeking groups in our educational and professional journeys. In our meetings, we had established a common understanding of social justice as framing and addressing systemic and root causes of inequalities in society. From learning from each other's experiences, we recognized the importance of building allyship in promoting social justice in dietetics. For these reasons, there was no hesitation to collaborate in presenting our shared experiences at the 8th Annual Critical Dietetics Conference in 2018. We felt it important to share this message with the dietetics community, and to offer examples and solutions for the barriers to equity and diversity within dietetic education for those in positions of leadership. This paper is a summary of our 2018 presentation. We describe our lived experiences as students from equity-seeking groups in dietetic education and professional socialization within the broader social context of systems of privilege and oppression in Canada. Our experiences showed the common and unique ways students respond to and navigate these systemic challenges and apply them to our professional journeys in dietetics and beyond.

In this paper, we refer to ourselves as "equityseeking" not only because we are members of various marginalized communities but also because we intend to claim a sense of agency for social transformation. However, when referring to examples of students experiencing similar forms of oppression such as racism, homophobia, or classism, without identifying or taking on the responsibility of advocating for social justice, we use the term "marginalized".

\section{Authors Profiles}

We offer here brief descriptions of the social locations that have shaped our experiences; they influenced our writing and informed the interpretation of our collective experiences. 
MW (she/her/hers) is a first-generation citizen of AfroCaribbean settler parents. She is a cis-gender woman and dietitian. Her professional and academic focus involves exploring and communicating the relationship between food stories, nutrition, and social justice.

ML (she/her/hers) is a settler of Chinese and European descent. She is a queer cis-gender woman, and registered dietitian. She aims to reduce health inequities by working with communities and advocating for social justice both within the profession and beyond.

EN (he/him/his) is an immigrant and settler of Chinese ancestry. He is a cis-gender queer man and a dietetic educator, who is interested in the application of social justice in dietetic education and pedagogy.

RM (she/her/hers) is a first-generation citizen of Ghanaian immigrant/settler parents. She is a cis-gender woman and registered dietitian who engages in social justice advocacy through community development and educating dietitians about equity and food justice.

\section{Methods}

We utilized the generative dialogue method (Heierbacher, 2011; Isaac, 1999) to collaboratively generate knowledge about our lived experiences and resilience through group conversation. This dialogue allowed us to share our own experiences, identify diversity issues within dietetics education, and consider potential solutions to address social justice using socialstructural and intersectional lenses.

During a meeting in October 2018, the four of us met to discuss our experiences with dietetic education and training using the generative dialogue method. To facilitate discussion, each of us brought three questions to the meeting relating to our experiences of oppression within dietetic education. Through deliberation, we generated six main questions and responded to them. In the Spring of 2019, we met again to identify three main themes from our conversation by critically reflecting upon our discussion and the meaning of our first gathering.

\section{Dialogue}

The following are the six main questions that were generated from our dialogue. We hope they will help facilitate and open the door to similar conversations by others:

I. How exposed were you to social justice issues in your studies and beyond? What were your expectations upon entering your programs?
2. What were your experiences going through the process of obtaining your credentials?

3. What kind of gaps did you notice in your studies? How did you fill them both in your program and personal endeavors? Did you consider unconventional opportunities?

4. How does your experience of marginalization influence the communities that you have chosen to serve?

5. Based on your race, gender, and sexual identity, lived experiences, and motivation to pursue dietetics, did you feel that you were represented or belonged?

6. What are some of the ways that you have reacted to the experiences of exclusion of other colleagues based on their social location or identities?

\section{Themes}

The three themes that emerged from reflecting on and analyzing our responses to these six questions included: barriers, seeking belonging, and resilience.

\section{Barriers}

We all expressed common barriers through our dietetic education journeys based on our social identities and our interest in social justice, equity, and inclusion in dietetics.

All of us had identified a shared expectation that our academic and career choices would inherently address social justice issues and solutions. However, despite introductory teachings on the social determinants of health and their impact on the clients and populations we would soon serve, we collectively found that there were gaps in our dietetic education. These gaps revealed the omission of the foundational contexts that establish and perpetuate the social barriers that we intended to address in our dietetic practice. This included the oppressive realities that we, as members of equity-seeking groups, were experiencing and continue to experience. Discussions and evidence regarding the meaning, historical context, and social implications of racism, immigration, colonization, privilege and oppression, intersectionality, 2SLGBTQ+ and allyship were not foundations in our dietetic educational experience. Subsequently, we faced the challenge of struggling to balance our required dietetic courses while seeking outside educational opportunities to learn about 
social justice that acknowledged our varying identities. For example, three of us took courses on health equity and diversity, while another took food history. These experiences echo those of other marginalized students across Canada. For example, Codjoe (200I) reported that Black university students in Edmonton found the curriculum to have little relevance to them and included racial biases. In the education setting, discussions regarding the "issues" of people in marginalized communities are often minimized to "one-off" topics of conversation (Brady, 2020, Joy \& Numer, 2018). More indepth and persistent conversations about these topics were only facilitated by specific educators with intentions to include social justice in their courses. Joy and Numer (2018) identify this exact barrier regarding 2SLGBTQ+ inclusion in dietetic education. Atkins \& Brady (2016) also highlight the issue of facilitating academic environments that perpetuate heteronormative views of the world. These normative views and skills, and the exclusion of those from marginalized communities set the norm for dietetic professionalization (MacLellan, Lordly \& Gingras, 20II); subsequently facilitating the barriers found in the next theme identified in our dialogue, Seeking Belonging.

\section{Seeking Belonging}

In attempting to navigate the barriers identified, we felt "othered" and excluded throughout our dietetic education journeys. In the classroom and placement settings, there were spaces where we felt that there were limited representations of our identities within the profession among peers, mentors, and colleagues.

"I felt like there was not enough representation of all aspects of my identity within the profession, amongst peers and colleagues."

"I was the only one in the program who wasn't white."

"I was the only Black person in the building during one of my placements."

This is of no surprise considering that research demonstrates that these are persistent experiences for students from marginalized groups (Atkins \& Brady, 2016; Greenwald \& Davis, 2001; Reamer, 2016; Suarez \& Shanklin, 2002; Warren, 2019; White, 2012). Through these feelings, we were motivated to seek opportunities for recognition and validation (acknowledgment) for our experiences within safe spaces. We sought to identify commonalities and engage in social justice conversations with those whom we perceived to be like-minded peers.
However, there was a definitive barrier to initiating conversations centered around equity, diversity, and inclusion. Often, when we attempted to incite these conversations with our peers (and mentors), we were faced with "crickets." These silences could be stemmed from avoidance in acknowledging positions of privilege, lack of competency in having political conversations about social justice and misconception that these topics are not within the scope of dietetics (Brady, 2020; Joy \& Numer, 2016; Reamer, 2016).

Allyship was also challenging to navigate. Allyship can be defined as "an active, consistent, and arduous practice of unlearning and re-evaluating, in which a person in a position of privilege and power seeks to operate in solidarity with a marginalized group" (Anti-Oppression Network, n.d.). Our practicum experiences revealed how a lack of diversity could result in the challenge of appreciating access to the small pool of marginalized mentors while balancing the pressure to follow certain previous paths or to be perceived as competition for specific and sometimes tokenistic roles.

"There have been experiences where marginalized dietitians have wanted to mold me into them. This resulted in both pros and cons because they were willing to share relevant and useful information with me, but also expected me to think the same way they did. This resulted in conflict when we did not agree."

Reamer (2016) highlights similar experiences that were apparent throughout both her education and internship placements. She writes about feeling a sense of disinterest from her fellow peers when speaking about social justice issues relevant to her social identity, which she attributes partly to her inability to find people in dietetics that are representative of her identity and share similar experiences. This lack of representation of social identities within the profession amongst students, mentors, educators, and practitioners is a common theme that emerges in other research as well (Suarez \& Shanklin, 2002; Warren, 2019; White, 2012).

In navigating the challenges associated with finding safe spaces, recognition, and acknowledgment, we established a sense of resilience that was applied to create support systems, self-care practices, and additional learning opportunities. 


\section{Resilience}

Studies have identified factors contributing to the success of marginalized students in their pursuit and completion of their education (Codjoe, 2001; Warren, 2019; White, 2013; Duran, 2019). Research by Warren (2019) and Duran (2019) discusses how community and subcommunity support systems and resources empower female African American dietitians and queer students, respectively. However, our experiences demonstrate success forged from directly opposite circumstances.

In seeking out recognition and belonging, we created our own paths or new ways to develop resilience through building relationships and community outside of the dietetic program. For example, two of us joined the student group that specifically focused on Black Health. We also learned to go beyond our own experiences in solidarity with others having similar and different social identities through social justice and inclusion such as signing up for an Indigenous Health elective. At the same time, similar to half of the responding dietetic students noted in Brady's research (2020), we too sought out learning opportunities to promote social justice and inclusion through courses in other disciplines such as social justice, human rights, and history. We also participated in advocacy opportunities to address issues such as food justice, intersectionality, anti-racism, and food insecurity.

Self-care and peer-support became necessary. We navigated the tensions from having to defend our positions against microaggressions, justify our own experience of marginalization (Reamer, 2016), and risk burnout. During the reflection that led to identifying and organizing the themes in this paper, we also realized the role of creating safe spaces for each other in bringing up critical conversations about social justice and inclusion in dietetics. While these conversations were challenging, we persisted in hopes of planting the seeds for social change.

\section{Discussion \& Relevance to (Critical) Dietetic Practice \& Education}

Our dialogue generated several recommendations for dietetic educators to support dietetic students from marginalized communities in their academic and professional journey. These recommendations can inform educators when considering holding similar reflective and social justice conversations while relieving the burden on marginalized students. They may also facilitate the equitable environment necessary for diversifying the practice.

\section{Recommendations for Dietetic Educators}

I. Identify Hidden Assumptions. Educators should name systems of oppression hidden within dietetic education curriculum and practice. How do classist, capitalist, colonial, racist, sexist, and cisheteronormative assumptions influence the way dietetic students are selected and socialized? Only by naming these assumptions and assessing their negative impacts can educators begin to address systemic barriers within the dietetic education processes and curriculum.

2. Acknowledge Privilege \& Avoid Tokenism. Educators should locate their positionality and privilege when engaging in critical conversations about oppression. Safe spaces for students should be fostered, however marginalized students should not be expected to speak for their marginalized communities. Safe spaces for one student might not be safe for another (Lordly, Lövestam, \& Ruhl, 2019). By locating their own privilege and positionality, educators can invite students to do the same.

3. Recognize Intersectionality in Dietetic Education. It is important for educators to identify and acknowledge intersectional oppressions, both in the critical analysis and interpretation of dietetic literature. This is relevant in both natural and social sciences courses. Intersectionality enhances understandings of how systems of oppressions include/exclude multiple social identities such as class, gender, race, and sexuality; and how these systems impact students.

4. Engage in Allyship. The lack of diversity within the profession contributes to how marginalized students are socialized. Given the responsibility that mentors and educators hold, there is an importance within these roles of creating the space in which marginalized students can grow and shape their practice. Mentors and educators should offer encouragement and support while recognizing the strengths of the perspectives that marginalized students bring from their specific identities and lived experiences.

\section{Conclusion}

Giroux (1994) informed us that a time would come when educators would be obligated to address and respond to issues of social injustice. The current political 
environment has inspired significant social justice advocacy within and outside of the academic realm. In order to address the ongoing systems of oppression perpetuated within the academic setting that influence the professional socialization and personal development of students, it is no longer appropriate for dietetic educators to ignore the hard questions. Now is the time to have these difficult conversations.

\section{Author Bios}

Mikahelia Wellington (she/her/hers) is a first-generation citizen of Afro-Caribbean settler parents. She is a cisgender and female dietitian. Her professional and academic focus involves exploring and communicating the relationship between food stories, nutrition, and social justice.

Meaghan Lee (she/her/hers) is a settler of Chinese and European descent. She is a cis-gender, able-bodied, queer woman, registered dietitian. She aims to reduce health inequities by working with communities and advocating for social justice both within the profession and beyond

Eric Ng (he/him/his) is an immigrant and settler of Chinese ancestry. He is a cis-gender queer male dietitian and a dietetic educator, who is interested in the application of social justice in dietetic education and pedagogy.

Rosie Mensah (she/her/hers) is a first-generation citizen of Ghanaian immigrant/settler parents. She is a cisgender and female registered dietitian who engages in social justice advocacy through community development and educating dietitians about equity and food justice.

\section{References}

Anti-Oppression Network (n.d). Allyship. https:// theantioppressionnetwork.com/allyship/

Atkins, J. \& Brady, J. (2016). Queer theory \& dietetics education: interrupting heteronormativity. Journal of Critical Dietetics, 3(I), 24-34. https://journals.library.ryerson.ca/index.php/ criticaldietetics/article/view/660/675

Brady, J. (2020). Social justice and dietetic education: Are we preparing practitioners to lead? Canadian Journal of Dietetic Practice and Research, 8:1-7. https://doi.org/10.3148/ cjdpr-2020-008

Codjoe, H. M. (200I). Fighting a 'Public Enemy'of Black Academic Achievement-the persistence of racism and the schooling experiences of Black students in Canada. Race Ethnicity and Education, 4(4), 343-375. https://doi. org/10.1080/13613320120096652

Duran, A. (2019). "Outsiders in a niche group": Using intersectionality to examine resilience for queer students of color. Journal of Diversity in Higher Education. https://doi. apa.org/doiLanding?doi= 10.1037\%2Fdhe0000144

Giroux, H. (1994). Doing cultural studies: Youth and the challenge of pedagogy. Harvard educational review, 64(3), 278-309. https://doi.org//0.17763/ haer.64.3.u27566k67qq70564

Greenwald, H. P. \& Davis, R. A. (2000). Minority Recruitment and Retention in Dietetics: Issues and Interventions. Journal of the American Dietetic Association, 100(8): 961-966. https://doi.org/10.1016/S0002-8223(00)00278-9

Heierbacher, S. (2011). Dialogue and Deliberation Processes. Berrett-Koehler Publishers.

Isaacs, W. (1999). Dialogue and the art of thinking together: A pioneering approach to communicating in business and in life. Crown Business.

Joy, P., \& Numer, M. (20|8). Queering educational practices in dietetics training: A critical review of LGBTQ inclusion strategies. Canadian Journal of Dietetic Practice and Research: A Publication of Dietitians of Canada, 79(2), 80-85. https:// doi.org/10.3148/cjdpr-2018-006

Lordly, D., Lövestam, E., \& Ruhl, J. (2019). Awakening the possibilities: an exploration of critical nutrition and dietetic training and education. In J. Coveney, S. Booth. (Eds), Critical Dietetics and Critical Nutrition Studies. Springer

MacLellan, D., Lordly, D., \& Gingras, J. (2011). Professional socialization in dietetics: A review of the literature. Canadian Journal of Dietetic Practice and Research, 72(1), 37-42. https://dcjournal.ca/doi/l0.3148/72.1.2011.37

Reamer, B. V. (2016). Lack of social support and acceptance as a person of color in dietetics. Journal of Critical Dietetics, 3(1), 21-23. https://journals.library.ryerson.ca/index.php/ criticaldietetics/article/view/657/672

Riediger, N. D., Kingson, O., Mudryj, A., Farquhar, K. L., Spence, K. A., Vagianos, K., \& Suh, M. (2019). Diversity and equity in dietetics and undergraduate nutrition education in manitoba. Canadian Journal of Dietetic Practice and Research : A Publication of Dietitians of Canada, 80(I), 44-46. https:// dcjournal.ca/doi/l0.3148/cjdpr-2018-034

Suarez, V. V. \& Shanklin, C. W. (2002). Minority Interns' Experiences During Their Dietetics Education and Their Recommendations for Increasing Diversity in Dietetics. Journal of the American Dietetic Association, 102(11): 16741677..

Warren, J.L. (2019). Diversity in dietetics matters: experiences and obstacles en route to registered dietitian practice. Journal of Critical Dietetics, 4(2), 38-50. https://journals. library.ryerson.ca/index.php/criticaldietetics/article/ view/1023/1299

White., J. (2012). "Hearing the voices": African American nutrition educators speak about racism in dietetics. Journal of Critical Dietetics, I (3); 26-35. https://criticaldieteticsblog. $\mathrm{com} / 2013 / 04 / 02 /$ hearing-the-voices-african-americannutrition-educators-speak-about-racism-in-dietetics/ https://criticaldieteticsblog.files.wordpress.com/2013/04/ journal-of-critical-dietetics-p26-35.pdf 